\title{
David Hume y el contractualismo
}

\author{
José Fernández SANTILLÁN \\ Tecnológico de Monterrey (Campus Ciudad de México) \\ jfsantillan@itesm.mx
}

Recibido: 26-02-2015

Aceptado: 08-10-2015

\begin{abstract}
Resumen
David Hume pertenece a la corriente filosófica llamada consecuencialista en la que se inscribe el utilitarismo. Esta tendencia fue contraria al normativismo, en la que se incluye el contractualismo. Aquí analizo la crítica hecha por Hume, desde la óptica utilitarista, al contractualismo. Los mayores filósofos del contractualismo son Thomas Hobbes, John Locke y Jean Jacques Rousseau. Hume esgrimió tres tipos de argumentos contra ellos: 1) histórico: el contrato social no tiene ninguna prueba histórica de haber existido, en consecuencia no puede ser presentado como sustento del Estado; 2) filosófica: no es el deber sino el interés lo que mueve a los hombres para formar la autoridad política; 3 ) social: en la conciencia del pueblo, no hay traza alguna del susodicho contrato.

El utilitarismo, ciertamente es una de las tendencias que ayudaron a finalizar la hegemonía teórica que el contractualismo había ejercido durante los siglos XVII y XVIII. Con todo y eso, desde el punto de vista histórico y social, los movimientos de liberación en muchas partes del mundo, en esa época, fueron inspirados por el contractualismo. Vale decir, desde el punto de vista filosófico el utilitarismo, ciertamente puso de relieve los orígenes empíricos del Estado, pero no su justificación normativa, racional. Hume entendió en toda su amplitud el contenido normativo del contractualismo que también inspiró y sigue inspirando la acción humana.
\end{abstract}

Palabras clave: contractualismo; normativismo; legitimidad; autoridad; política; utilitarismo; consecuencialismo; costumbres; mandato; obediencia.

\section{David Hume and contractualism}

\begin{abstract}
David Hume belonged to the consecuencialist philosophical tendency, in which is included utilitarianism. This tendency was opposed to the normativism philosophy, in which is enrolled contractualism. This article analyzes the critique made by David Hume, from the utilitarianism perspective, against contractualism. The major philosophers of contractualism are Thomas Hobbes, John Locke and Jean Jacques Rousseau. Hume implemented three arguments in opposition to them: 1) historic: the social contract does not have any practical testing. Therefore it could not be presented as the foundation of the state; 2) philosophical: it is not the duty, but the interest that moves men to seek the formation of the political authority; 3) social: in the consciousness of the people, there is no trace of the social contract. Utilitarianism was one of the philosophical tendencies that finished the theoretical hegemony that contractualism had during the XVII and the XVIII centuries. Nonetheless from the historical and social point of view, the liberalization movements in many parts of the world, at that time, were inspired by contractualism. It means that from the theoretical point of view, utilitarianism, certainly, stressed the empirical origins of the state but not the rational justification of the political Authority. Hume was unable to understand the normative force that contractualism owns, which inspires human action.
\end{abstract}

Key words: contractualism; normativism; legitimacy; authority; politics; utilitarianism; consequentialism; custom; mandate; obedience.

\section{Referencia normalizada}

Fernández Santillan J. (2016): “David Humer y el contractualismo”, Política y Sociedad, 53 (2), pp. 463-483. 
Sumario: Introducción. 1. El iusnaturalismo. 2. El utilitarismo. 3. La quimera del contrato social. 4. Conclusiones. 5. Bibliografía.

\begin{abstract}
$* * *$
Agradecimientos

Mis estudios sobre el contractualismo y el anti-contractualismo comenzaron a principios de los años 80 en la Universidad de Turín bajo la guía de mi maestro Norberto Bobbio, con él tengo contraída un deuda de gratitud, al igual que con su sucesor en la cátedra de filosofía política Michelangelo Bovero y también con otro de sus alumnos Luigi Bonanate. Como se verá el enfoque aquí expresado es propio de la llamada "Escuela de Turín de Filosofía Política". Este ensayo lo comencé a elaborar en una instancia de investigación en la Universidad de Georgetown en el verano de 2013, de ahí agradezco el apoyo de John Bailey. Lo continué en el Tecnológico de Monterrey CCM, mi casa de trabajo, de esta institución agradezco a Inés Sáenz, Dora Elvira García, Julio Rubio e Iliana Rodríguez. Lo terminé en mi periodo sabático como Fullbright Scholar in Residence (SIR) de la Universidad de Baltimore, de esa institución educativa agradezco en especial a Alan Lyles y Roger Hartley.

También deseo expresar mi reconocimiento por la ayuda que me prestaron para elaborar este ensayo a mis asistentes de investigación en el Tecnológico de Monterrey y contratadas por el CONACyT en mi calidad de Investigador Nacional Nivel 3: Anna Elena Montero, Ana Laura Zarco, Daniela Flores y Helga Jáuregui.
\end{abstract}

\title{
Introducción
}

Parto de una idea básica: la historia del pensamiento político es una larga cadena de rivalidades entre corrientes antagónicas. Uno de esos binomios contradictorios es el constituido por el utilitarismo y el contractualismo. En el presente estudio de filosofía política vamos a la raíz de esa disputa con base en la argumentación planteada por David Hume (1711-1776), desde el lado utilitarista, quien refutó las tesis del contractualismo. Para llevar a cabo dicho análisis destacaremos, en primer lugar, aquellos que nos parecen los rasgos fundamentales del contractualismo para después, en un segundo momento, poner atención en la crítica de Hume a esa escuela de pensamiento a la que, en términos modernos, también se le conoce como la escuela moderna del derecho natural.

Se sabe que la teoría política y jurídica del derecho natural tiene un alto grado de complejidad. Lo que hago aquí es continuar el estudio filosófico que comencé en Turín bajo la guía de Norberto Bobbio en 1980 sobre el contractualismo y el anticontractualismo. (Fernández Santillán, 1988; Fernández Santillán, 1996; Fernández Santillán, 2011a; Fernández Santillán, 2011b). Lo que ha hecho la llamada escuela de Turín, como veremos, es destacar los rasgos característicos que unen a los autores iusnaturalistas para así poder confrontarlos con otras corrientes de pensamiento político y jurídico. 


\section{El Iusnaturalismo}

La escuela del derecho natural dominó la filosofía política y jurídica entre los siglos XVII y XVIII. Los autores más representativos de esta doctrina son Thomas Hobbes (1588-1679), John Locke (1632-1704) y Jean Jacques Rousseau (1712-1778). Si bien sus propuestas políticas son diferentes e incluso contrapuestas: el absolutismo (Hobbes), el liberalismo (Locke) y la democracia (Rousseau), ellos coinciden en la utilización de una misma orientación teórica.

Ellos dividieron el campo de análisis en dos grandes áreas: el estado de naturaleza y el estado civil; el estado de naturaleza es, al mismo tiempo, condición no-política y situación salvaje, mientras que el estado civil significa, a la vez, condición política y condición civilizada. El paso de una condición a otra se realiza no de manera natural, sino de manera voluntaria, mediante un contrato.

\subsection{Thomas Hobbes}

Este filósofo es considerado el padre de la escuela del derecho natural. (Bobbio, 1973: 9-34; Bobbio e Bovero, 1979: 17-109; Bobbio y Bovero, 1986: 13-145) Para él, el estado de naturaleza es una condición de anarquía. Allí, en vista de que no hay una autoridad constituida, nadie está seguro de conservar la vida. En el estado de naturaleza priva la desconfianza recíproca; cada quien tan sólo puede confiar en su propia fuerza y maña para mantener la existencia.

Para Hobbes, el Estado es un artificio creado por la voluntad del hombre. Su establecimiento implica un salto cualitativo de una realidad natural a otra realidad nonatural. De acuerdo con este filósofo los hombres no nacen con un instinto natural a la sociabilidad, como lo creía Aristóteles (1988: 49-50); más bien, los hombres son seres aislados, egoístas.

En el estado de naturaleza nadie puede establecer un domino permanente sobre los demás porque, en la práctica, hay una igualdad entre los individuos. Se trata de una observación realista y descarnada. Esta igualdad es presentada por Hobbes bajo tres aspectos: a) una igualdad de hecho, o igualdad de las fuerzas físicas, habilidad y capacidades intelectuales; b) una igualdad de derecho, o derecho de cada cual a todas las cosas; c) una igualdad de las pasiones, especialmente la codicia irrefrenable de poder. Al acumularse estas condiciones dan lugar a que el estado de naturaleza sea un estado de guerra. (Fernández Santillán, 1988: 21).

Hobbes tiene una idea negativa del hombre; para él el ser humano es malo por naturaleza. La codicia lo lleva a procurarse riquezas y privilegios sin preocuparse de las consecuencias que ello acarree. Lo que lo mueve, fundamentalmente, son la competencia, la desconfianza y la gloria pero, sobre todo, el deseo insaciable de poder. (Hobbes, 1982: 161)

El ambiente conflictivo se agrava por la índole pasional del ser humano: cada quien trata de satisfacer su egoísmo y presunción dañando a los demás. Todos tratan de huir del mal mayor, la muerte. (Hobbes, 1971: 86) En esta situación de incertidumbre, Hobbes reconoce que los individuos tienen el derecho de ver por su propia conservación. De hecho, se trata de un derecho innato con el que todos nacemos. El derecho natural 
es la libertad que cada quien tiene de hacer todo aquello que esté a mi alcance para garantizar mi vida.

Debemos entender que el estado de naturaleza de Hobbes y de todos los contractualistas es una pura idea del intelecto, es decir, una hipótesis. Recurren a esa figura para indicar una situación recurrente del género humano; una situación en la cual se vienen a encontrar los individuos cada vez que no hay autoridad: "Lo que Hobbes quiere decir al hablar de guerra de 'todos contra todos' es que allí donde se verifican las condiciones que caracterizan al estado de naturaleza, éste es un estado de guerra de todos los quienes se encuentran en esa situación." (Bobbio, 1979b: 290) Sobre el carácter hipotético de esta condición G. Tarantino observa: "este estado de naturaleza, más que la afirmación de una época histórica realmente existente, es para Hobbes...el reconocimiento lógico de la condición en la que se encontraría la vida humana fuera de la sociedad civil." (Tarantino, 1905: 77) Si hubiese existido en todos los tiempos y en todos los lugares la humanidad hubiese desaparecido desde hace tiempo.

Pero existen dos fuerzas que impulsan al hombre a salir del estado de naturaleza: el miedo a una muerte violenta y, particularmente, la razón. Las leyes de naturaleza son máximas de prudencia dirigidas a la autoconservación. La primera de ellas aconseja "buscar la paz." (Hobbes, 1982: 190).

El mecanismo a través del cual se logra la salida del estado de naturaleza, como hemos dicho, es el pacto; convenio que da lugar al estado civil. Cada hombre renuncia absolutamente a los derechos y a la fuerza naturales en favor de una autoridad seleccionada de común acuerdo a fin de preservar la propia existencia.

Con el pacto se crea una fuerza unificada que hace a los hombres mantener sus promesas: "Los pactos que no descansan en la espada no son más que palabras, sin una fuerza para proteger efectivamente al hombre." (Hobbes, 1982: 223-224) En el sistema de Hobbes el bien supremo es la vida y para protegerla los hombres se ponen de acuerdo para transferir voluntariamente todos sus derechos (excepto el derecho a la vida) y todos sus poderes al soberano (sea este una persona o una asamblea) con el objeto de que la vida les sea preservada. Por lo que respecta al soberano, éste adquiere todas las facultades y todo el poder, de manera que él es el único capaz de decidir que está bien y que está mal para garantizar la vida de sus súbditos y la paz en el Estado.

El pacto de unión propuesto por Hobbes es un pacto de alienación total de los derechos naturales, excepto el derecho a la vida: "Ninguno por cualquier cosa que haya pactado, se puede obligar a no oponerse a quien quiera asesinarlo, herirlo, o causarle cualquier lesión." (Hobbes, 1971: 106).

El paso del estado de naturaleza a la sociedad civil es el paso que marca la desaparición de la pluralidad de los poderes individuales contrapuestos entre sí y la aparición de la unidad del poder político, al cual todos los coasociados se someten. Este cambio es factible gracias a la estipulación del pacto de unión. La fórmula del pacto de unión concebido por Hobbes es: "Yo autorizo y cedo el derecho de gobernarme a este hombre o a esta asamblea de hombres a condición de que también ustedes cedan sus derechos a él y autoricen todas sus acciones de igual modo." (Hobbes, 1982: 227). 
En la tradición contractualista el primer momento (societatis) transforma una multitud en un pueblo, mientras que el segundo (subiectio) hacía de un pueblo una civitas. (Bobbio e Bovero, 1979: 63)

El pacto es el fundamento de legitimidad de la convivencia social. Y el Estado se instituye, precisamente, para garantizar la vida de los coasociados. Desaparece la pluralidad de poderes dispersos y se establece el poder único del Estado.

\subsection{Jean Jacques Rousseau}

Una variación dentro del modelo iusnaturalista es la de Jean Jacques Rousseau. Para este autor el estado de naturaleza no es de guerra, sino de paz. En consecuencia, no lo califica negativamente como una situación de conflicto y destrucción entre los hombres. Para él, por el contrario, la "edad de oro" fue una condición en la que el ser humano pudo vivir de manera independiente sobre todo porque se bastaba a sí mismo. Es la figura del "buen salvaje" descrita en el Discurso sobre el origen de la desigualdad entre los hombres. Allí, el ginebrino, les achaca a Thomas Hobbes y a John Locke el haber errado en la construcción del estado de naturaleza atribuyéndole al hombre salvaje rasgos que sólo pueden encontrarse en el hombre civilizado:

Los filósofos que han examinado los fundamentos de la sociedad, han sentido la necesidad de remontarse hasta el estado de naturaleza, pero ninguno de ellos ha tenido éxito. (Rousseau, 1964a: 132)

Para Rousseau el verdadero hombre de naturaleza no es malo ni está agitado por las pasiones; carece de aquellos vicios que, indebidamente, se le había atribuido Hobbes. Esos defectos sólo pueden ser adquiridos a través de un largo proceso de civilización. El buen salvaje perdió su pureza por causas externas como catástrofes naturales, el ataque de otras especies o cambios climáticos. Eso lo obligó a buscar la ayuda de sus semejantes. Así, adquirió características diferentes de las que tenía en un principio. Nacieron las pasiones, la competencia, la ambición, el deseo de causar daño y la maldad. Por eso, en su investigación sobre la evolución del ser humano, Rousseau quiere saber cuáles son las características innatas y cuáles las adquiridas.

La hipótesis histórica es necesaria en cuanto, dice este autor, hay que actuar como los científicos: elaboran algunas suposiciones acerca de cómo debió haber sido el origen del universo para saber cuál es el lugar que ocupa nuestro mundo en el cosmos. (Rousseau, 1964a: 123) Al comienzo el hombre era un ser instintivo pero, a diferencia de la bestia, tiene una cualidad que lo distingue, la libertad.

Para llevar a cabo su descripción histórica recurre a la separación del significado "sociedad civil", es decir, como condición civilizada y como condición política. Para Hobbes estos dos conceptos eran correspondientes. Para Rousseau, en cambio, el proceso de civilización implica una transformación gradual en el cual se profundiza la dependencia respecto de los otros hombres. Cada paso adelante implicó el reforzamiento de la dependencia, la desigualdad y la opresión.

Para Rousseau, a semejanza de los demás iusnaturalistas, el hombre no tiene una inclinación natural a la sociabilidad; la sociabilidad sólo se manifiesta tardíamente en 
el curso de la evolución humana. Así, surgieron las familias y las aldeas. Los pueblos pasaron de ser nómadas a sedentarios.

La constitución de la propiedad es una etapa fundamental para establece la sociedad civil en cuanto civilizada, pero aún no política. (Rousseau, 1964a: 164) La propiedad acarrea una determinada forma de desigualdad, aquella entre propietarios y nopropietarios.

Se registran conflictos entre ricos y pobres. Ya había propiedad, pero no había alguna autoridad que la garantizara. Por eso, los ricos echan mano de la astucia: le proponen a los pobres estipular un pacto para soluciona los antagonismos y como garantía (aparente) de seguridad. Tal acuerdo es, según dijeron los propietarios, la recuperación de la igualdad y la libertad; pero, en realidad es la institucionalización de la opresión y la desigualdad. Con esa argucia los ricos legitiman su dominio. Por eso Rousseau califica este primer pacto como una "razón especiosa" (un engaño): "todos corrieron al encuentro de sus cadenas creyendo asegurar la libertad." (Rousseau, 1964a: 177) El proceso degenerativo no se detiene: las pasiones y los vicios se refuerzan.

Con la institucionalización de la sociedad civil (en cuanto sociedad política) por medio del pacto inicuo aparece un segundo tipo de desigualdad, aquella entre poderosos y débiles. La corrupción política precipita en la tiranía. (Rousseau, 1964: 191). Se trata de la caída al estado de naturaleza, pero completamente distinto al primero del que habló en el Discurso sobre el origen de la desigualdad entre los hombres. Uno es de pureza, otro es de degradación; en el primero dependía de la naturaleza, en el segundo depende de los hombres; en uno no tenía pasiones, en el otro está carcomido por la ambición.

Por eso es que en el Contrato social comienza diciendo "el hombre ha nacido libre y por todas partes está entre cadenas." (Rousseau, 1964b: 351). Con eso recuerda y retoma aquello que había dicho en el Discurso sobre el origen de la desigualdad entre los hombres: "todos corrieron al encuentro de sus cadenas creyendo asegurar la libertad." (Rousseau, 1964a: 177) y que ya hemos citado aquí. En tales circunstancias es preciso establecer otro pacto, el que funda la república. El nuevo contrato ya no estará orientado a profundizar las desigualdades y el dominio (tal era el contenido del contrato de los ricos), sino que resolverá las causas del conflicto, eliminando la injusticia, es decir, estará encaminado a permitir el ejercicio de la libertad e instaurará la igualdad: igualdad y libertad para el pensador de Ginebra son los valores fundamentales que inducen a los hombres a construir una verdadera asociación política.

El problema que se plantea Rousseau es: "Encontrar una forma de asociación que defienda y proteja con toda la fuerza común la persona y los bienes de cada asociado, y por la cual cada uno, uniéndose a todos, no obedezca sino a sí mismo y permanezca igualmente tan libre como antes." (Rousseau, 1964b: 360). Dilema difícil de resolver. No obstante, lo soluciona en los siguientes términos: "Cada uno de nosotros pone en común su persona y todo su poder, bajo la suprema dirección de la voluntad general, y todos nosotros en cuerpo recibimos a cada miembro como parte inseparable del todo." (Rousseau, 1964b: 361) Es la fórmula del contrato social que funda la república ¿Qué significa esto? Que cada uno formará parte de la asamblea soberana y, por tanto, que todos mandan (citoyen) y todos obedecen (sujet) a la vez. Uniéndose a todos no 
obedece a nadie en específico. Y, en efecto, permanece tan libre como antes. Incluso, en la república será más libre porque la libertad natural se transforma en libertad civil. De allí su definición: "libertad es obedecer a la ley que nos hemos dado." (Rousseau, 1964b: 365).

En estas circunstancias sólo es necesario el pacto de asociación (societatis); ya no se requiere el pacto de sumisión (subiectio) como en el caso de Hobbes. Porque todos se comprometen a obedecer al cuerpo colectivo de la asamblea soberana. No se someten a una persona como en el caso de la monarquía a la que favorecía Hobbes.

Los súbditos de Hobbes, en efecto, no les queda más que callar y obedecer, en cambio, los ciudadanos de Rousseau tienen que dialogar y participar. Por ello, le da tanta importancia a la educación como factor de transformación de las personas. De allí, precisamente, la importancia que le otorga a su tratado sobre la educación, $E l$ Emilio (Rousseau, 1969).

Esta peculiaridad del pensamiento de Rousseau fue captada por Norberto Bobbio en los siguientes términos: "No se entiende a Rousseau si no se comprende que a diferencia de todos los demás iusnaturalistas para los cuales en Estado tiene el propósito de proteger a los individuos, para Rousseau el cuerpo político que nace del contrato social tiene la misión de transformarlo." (Bobbio e Bovero, 1979: 68)

Esto es posible porque el sistema de filosofía política de Rousseau es dinámico. Por eso le es posible hacer una descripción del buen salvaje (el hombre como fue), del hombre de la civilización corrupta (el ser humano como es) y del hombre como puede ser (el ciudadano de la república).

Con todo y eso, para los fines de nuestra exposición, vale la pena insistir: por muy diferentes que sean sus propuestas políticas, a Hobbes y a Rousseau, junto con los autores iusnaturalistas, en especial respecto de Locke que es objeto de referencia por parte de Hume, los une un mismo modelo filosófico. Norberto Bobbio ha puntualizado el alcance del modelo iusnaturalista en los siguientes términos: "Hablando de 'modelo' quiero dar a entender inmediatamente que en la realidad histórica un proceso de formación de la sociedad civil como el ideado por los iusnaturalistas jamás ha tenido lugar; en la evolución de las instituciones de las que ha nacido el Estado moderno se ha dado el paso del Estado feudal, al Estado estamental, del Estado estamental a la monarquía absoluta, de la monarquía absoluta al Estado representativo; pero el Estado como un producto de la voluntad racional, como es al que se refiere Hobbes y sus seguidores, es una pura idea del intelecto." (Bobbio y Bovero, 1979: 37-38) En efecto, el modelo iusnaturalista es un modelo normativo.

En el lado opuesto a la ética normativa está la ética de las consecuencias; esto es, no lo que está antes de la acción, sino lo que está después. La doctrina contraria al normativismo es el consecuencialismo. Max Weber estableció la diferencia entre ambas de la siguiente manera:

Tenemos que ver con claridad que toda acción éticamente orientada puede ajustarse a dos máximas fundamentalmente distintas entre sí o irremediablemente opuestas: puede orientarse conforme a la 'ética de la convicción' o conforme a la 'ética de la responsabilidad'.” (Weber, 1969: 163) 
Como decíamos, en el primer caso están las corrientes normativistas, una de las cuales es el iusnaturalismo; en el segundo caso están las corrientes consecuencialistas, una de las cuales es el utilitarismo.

\section{El Utilitarismo}

\subsection{Jeremy Bentham}

El autor que es considerado el padre del utilitarismo es Jeremy Bentham (17481832). Para él es absurdo tratar de encontrar un fundamento de las acciones humanas en principios morales que ordenan comportarse de conformidad con un mandato incondicionado de la razón según la ética normativa. Afirmó, en contraste, que en las acciones de los hombres tienen que estar referidas a un fin según los principios del consecuencialismo.

En su obra Introducción a Los principios de moral y legislación, aparecida en 1789, criticó la filosofía inspirada en el deber, o sea, el iusnaturalismo. Propuso, para contrastarla, un criterio distinto: "La naturaleza ha puesto al hombre bajo el gobierno de dos pautas soberanas, el dolor y el placer. Por ello no tiene sentido señalar lo que se debe hacer así como determinar lo que deberíamos hacer. De una parte, la norma de lo correcto y equivocado, de otra parte, el vínculo entre causas y efectos, están asegurados en su trono. Ellos nos rigen en todo lo que hacemos, en lo que decimos, en lo que pensamos." (Bentham, 1948: 1) La tesis fundamental del utilitarismo es que los hombres buscan acercarse al placer y huir del dolor.

En el centro de la teoría utilitarista no está el deber, sino el interés. En consecuencia, una acción será más racional en la medida en que ella produzca más beneficios. A fin de cuentas de lo que se trata es de maximizar las ganancias y minimizar las pérdidas.

Hay que añadir un dato importante para que podamos hilar nuestros subsecuentes planteamientos: El utilitarismo es una doctrina individualista; por tanto, se opone al comunitarismo. Así lo dejó asentado Bentham: "La comunidad es un cuerpo ficticio compuesto por personas concretas consideradas como miembros de dicha comunidad. Por tanto, ¿qué es el interés de la comunidad? Pues ni más ni menos, la suma de intereses de los miembros que la componen." (Bentham, 1948: 3) Las instituciones y las leyes han de valorarse de conformidad con esa idea: "La felicidad de los individuos que componen una comunidad, esto es, sus placeres y seguridad, es el único propósito que el legislador debe tener en cuenta, la sola medida de conformidad con la cual cada individuo, en lo que dependa del legislador, debe hacer para conformar su manera de proceder." (Bentham, 1948: 24).

Bentham no cree en que haya habido un estado de naturaleza así como lo describen Hobbes y Rousseau. (Bentham, 2010: 66) Juzga al contrato social como una ficción. Reconoce, textualmente, en su libro Un fragmento sobre el gobierno, que "esta quimera ha sido eficazmente demolida por el Señor Hume.” (Bentham, 2010: 82). 


\section{La quimera del contrato social}

David Hume (1711-1776), efectivamente, rechazó el iusnaturalismo moderno y con ello a la teoría del contrato social. Este pensador criticó la "falacia" del estado de naturaleza. En su libro Investigación acerca de los principios de la moral, hace referencia a la ficción de la "edad de oro" tal como la imaginó Rousseau, esto es, como una condición de pureza originaria; pero también la emprende contra el estado de naturaleza como estado de guerra según lo figuró Hobbes. Véase el siguiente fragmento:

La poética ficción de la edad de oro es, bajo ciertos aspectos, uno y lo mismo con la ficción filosófica del estado de naturaleza; sólo que la primera es representada como la condición más atrayente y pacífica, que pueda ser imaginada; en tanto que, el segundo es dibujado como una situación de guerra recíproca y violencia, acompañada por la más extrema indigencia. En el primer origen de la humanidad, se nos dice, su ignorancia y naturaleza salvaje eran tan preponderantes que ninguno podía confiar en el otro, sino que cada cual debía confiar para su propia protección y seguridad en su sola fuerza y astucia. Jamás se oyó hablar de la ley; no se conocieron reglas de justicia; ninguna distinción de propiedad fue respetada. El poder fue la única medida de derecho, y una perpetua guerra de todos contra todos fue el resultado del indómito egoísmo y barbarie de los hombres. (Hume, 1986: 189)

De acuerdo con Hume, la idea del estado de naturaleza, como guerra de todos contra todos, no se sostiene en pie. Lo que, en cambio, sí cree es que los hombres nacieron ya aptos para la sociabilidad, es decir, se adhiere al modelo aristotélico de la sociabilidad como característica innata del hombre. Para él, los seres humanos, desde un origen, crecieron en el seno de la familia. En ella los individuos se educan bajo ciertas normas de conducta. Reglas que sirvieron para la convivencia pacífica. De esta manera los seres humanos sobrevivimos como especie.

Así como se burla del estado de guerra, también se mofa del contrato social (Brownsey, 1978: 132). En un apartado de los Ensayos sobre moral, política y literatura, específicamente en la parte II, capítulo 12 dedicado al "Contrato originario", señala:

Si tú anduviese predicando por todas partes que los vínculos políticos se basan del todo en el consenso voluntario y en una promesa recíproca, el juez inmediatamente te mandaría a prisión como sedicioso por debilitar los vínculos de la obediencia, si no es que tus amigos te internarían como delirante por andar pregonando semejantes disparates. (Hume, 1992: 470)

Incluso, en el remoto caso de haber existido un acuerdo originario, éste sería tan antiguo que nadie se acordaría de él. Los cambios sociales han sido de tal índole que aquella primera convención resultaría inservible.

Lo que señala este pensador es que: "Casi todos los gobiernos que existen en el presente o que queda traza y registro en la historia, fueron fundados originalmente en la usurpación o en la conquista o en ambos sin pretensión alguna de consenso abierto o sujeción voluntaria del pueblo." (Hume, 1992: 471) Para él, en la base de los estados no está el consenso, sino la fuerza. 
Empíricamente no hay manera de demostrar la existencia de un contrato social como fundamento del Estado. De lo que, en cambio, sí hay rastro es de combates sangrientos de muy diversa índole. Los hombres que se someten al poder político no lo hacen por aceptación espontánea, sino por la amenaza de la coacción.

Ciertamente, lo ideal hubiera sido que los individuos hubiesen tenido una inclinación natural a la justicia. Así se hubieran mantenido en una condición de absoluta libertad sin tener que someterse a una autoridad. En un pasaje que recuerda al estado de naturaleza pensado por John Locke (Locke, 1980: 287-300) como una situación de paz en la que los hombres respetan las propiedades de los demás, David Hume escribe:

Si todos los hombres tuviesen un respeto irrestricto por la justicia que se abstuviesen espontáneamente de la propiedad de los demás, hubiesen permanecido para siempre en una condición de absoluta libertad sin tener que someterse a un magistrado o a una sociedad política. (Hume, 1992: 474)

Allí prevalecería la razón y la concordia; no habría necesidad de la autoridad pública para garantizar la paz.

Pero - continúa diciendo Hume - este es un estado de perfección del que la naturaleza humana es considerada incapaz. Incluso, si todos los hombres poseyeran entendimiento tan perfecto como para conocer siempre sus verdaderos intereses jamás se hubiesen sometido si no a una forma de gobierno que estuviese basada en el consenso y discutida en todas sus partes por cada miembro de la sociedad. Pero este estado de perfección es muy superior a la naturaleza humana. Razón, historia y experiencia nos muestran que todas las sociedades políticas tienen un origen mucho menos definido y regular. (Hume, 1992: 474)

En la concepción humuana no hay lugar para especulaciones normativas. Las situaciones ideales son confinadas al reino de la contemplación utópica. Más bien invita a poner los pies en la tierra: ¿qué pasaría si una sociedad se quedara sin autoridad?:

A decir verdad, no hay cosa más terrible que la disolución total del gobierno que da libertad a la multitud y hace depender la determinación o formación de un nuevo ordenamiento de un cierto número de personas que casi se acerca al del entero cuerpo popular. Pero la totalidad no se alcanza jamás. Pero, entonces, toda persona sabia desea ver, a la cabeza de un ejército poderoso y obediente, un general, que pueda alcanzar rápidamente el objetivo y dé al pueblo un jefe, que ese pueblo no está en posibilidad de seleccionar por sí mismo. En tan escasa medida la realidad corresponde con aquella noción filosófica. (Hume, 1992: 472)

Aquí destaca su animadversión contra la anarquía y la prioridad que le otorga al orden. También sobresale el desprecio por el expediente contractualista: a su entender, al momento de aplicarlo en la realidad, simplemente, no embona: no vamos a esperar a que se tome el parecer de cada uno de los miembros del cuerpo social para resolver 
la urgencia del desorden. Lo que se requiere inmediatamente es que alguien tome el mando para comandar un ejército e imponer el orden.

Ahora bien, los contractualistas dijeron con claridad que no todos las generaciones tenían que refrendar el pacto social, sino que hay un consenso tácito. Hay alguna forma de manifestar la adhesión a la sociedad política ya constituida a la que John Locke, por ejemplo, llama, precisamente, en el siguiente fragmento del Segundo ensayo sobre el gobierno civil "consentimiento tácito":

Existe una distinción corriente entre consentimiento expreso y consentimiento tácito, que podrá aplicarse a nuestro caso actual. Nadie pone en duda que el consentimiento expreso de un hombre para entrar en una sociedad lo convierte en miembro perfecto de la misma, en súbdito de aquel gobierno. La dificultad estriba en ponerse de acuerdo sobre lo que debe entenderse por consentimiento tácito y hasta qué punto vincula éste, es decir, hasta qué punto se considerará que una persona ha consentido, sometiéndose de ese modo a un gobierno determinado, en los casos en que no ha manifestado expresamente ese consentimiento. (Locke, 1980: 365-366)

Polemizando con esta apreciación lockeana, Hume sostiene que si se piensa que se puede considerar consentimiento tácito (tacit conset) al dominio de un Príncipe bajo el cual una persona vive (gobernante al cual uno puede abandonar voluntariamente) y se le promete obediencia, acaso pueda responderse que ese consenso implícito sólo puede tener lugar cuando una persona imagine que el asunto depende de su libre albedrío. Pero donde él estima (como todos los hombres nacidos bajo regímenes establecidos) que por su nacimiento él debe obediencia a un determinado Príncipe o a una cierta forma de gobierno, sería absurdo inferir un consenso o alguna elección que se pueda llevar a cabo. Es decir, como si todos tuviesen en mente el citado contrato social como alternativa para quedarse o abandonar el país en el que nacieron.

Para hacer aún más explícito su planteamiento contra el consentimiento tácito Hume recurre a las metáforas de un campesino y de un tripulante involuntario de un barco:

¿Acaso podemos decir seriamente que un pobre campesino o artesano pueda decidir libremente dejar su país, cuando él no conoce alguna lengua extranjera o costumbre foránea, y vive al día con el escaso ingreso que gana? ¿De la misma manera, se podrá decir por ventura que un hombre, puesto en un barco, consintió libremente el poder de un capital, a pesar de que fue llevado a bordo mientras dormía y deberá saltar al mar y morir al momento de dejar la nave. (Hume, 1992: 475)

El argumento del que echa mano es de carácter empírico: no hay manera de sustentar la presencia de ese consentimiento tácito allí donde no se tiene noticia de que haya existido un contrato originario. Así como no hay una conexión lógica entre causa y efecto en términos contractuales, tampoco hay manera de confirmar la presencia del expediente contractual en la conciencia de las personas. De allí precisamente el ejemplo del campesino y del tripulante involuntario: ni el primero tiene en mente abandonar su terruño, ni el segundo piensa en saltar al mar con tal de no seguir soportando el domino del capitán del barco. Ni tienen voluntad ni tienen posibilidad de dejar el lugar en el 
que ya están. Objetivamente, ambos ejemplos son puestos para resaltar el sinsentido de pensar que el contrato está grabado en la mente y espíritu de las personas.

Pero, entonces, si rechaza el expediente contractual ¿en qué bases descansa la autoridad política según Hume? La respuesta que proporciona recorre el siguiente itinerario argumentativo: nuestros instintos primarios nos llevan a abandonarnos a una libertad sin límites o a buscar el dominio sobre los demás "únicamente la reflexión nos mueve a sacrificar esas pasiones tan fuertes a los intereses de la paz y del orden público. Un poco de experiencia y observación es suficiente para enseñarnos que la sociedad no puede subsistir sin la autoridad de los magistrados y que esta autoridad rápidamente cae en el desprecio allí donde no se le presta la debida obediencia. La constatación de estos obvios intereses generales es la fuente de toda obediencia y de la obligación moral que a ella le brindamos." (Hume, 1992: 480) Luego entonces, los hombres se someten a la autoridad con base en los intereses y las necesidades de la sociedad, no a partir de alguna supuesta promesa que le han formulado al soberano: "Si se me preguntase la razón de la obediencia que estamos obligados a prestarle al gobierno, respondería de inmediato: porque de otra manera la sociedad no podría subsistir. Y esta es una respuesta clara e inteligible para todos los hombres." (Hume, 1992: 481) Pero la respuesta de los contractualistas es, en cambio, "porque debemos mantener la palabra dada". El problema es que nadie que no haya sido adiestrado filosóficamente puede entender y apreciar - dice Hume - en qué consiste esta respuesta. Y vamos a escudriñar en los orígenes de la historia encontraremos que, generación tras generación la verdadera fuente del poder fue "la usurpación y la violencia." Juzga que sólo una falsa filosofía con capciosas reglas de lógica puede situar los fundamentos del poder en otro terreno. Fuera de esas artimañas especulativas: "La obligación general que nos liga al gobierno es el interés y las necesidades de la sociedad; y esta obligación es muy fuerte." (Hume, 1992: 486).

Hume asienta su teoría de la obligación política sobre bases empíricas, no sobre bases especulativas. Los intereses y las necesidades son su argumento para sustentar la relación mandato-obediencia, no la libre y voluntaria aceptación de la autoridad. En consecuencia, rechaza la especulación metafísica que sólo conduce a paradojas repugnantes: "Y nada prueba más claramente que una teoría de este tipo es errónea que encontrar a la práctica y a la opinión de todas las naciones y de todas las épocas. La doctrina que funda todo gobierno legítimo sobre un contrato originario, o sobre el consentimiento del pueblo, es obviamente de este tipo, y el más ilustre de sus partidarios [se refiere a John Locke], no ha tenido escrúpulos en afirmar, siguiendo su espíritu, que la monarquía absoluta es inconsistente con la sociedad civil, y no puede por tanto, ser una forma de gobierno civil y que el poder supremo no puede, en un estado tomar de a un individuo mediante gravámenes e impuestos parte de su propiedad sin su consentimiento y el de sus representantes." (Hume, 1992: 486-487) Empero, para Hume, no hay autoridad que en su actuación tenga un pensamiento moral que lleve a razonamientos tan lejanos de la práctica general de las personas.

Lo que, en cambio, sostiene Hume es que el orden social es mantenido por el gobierno, y la obligación que se le debe a los magistrados. Ese respeto vale para nuestros conciudadanos. Si no hay orden no puede haber convivencia civilizada. (Hume, 1992: 
38-39) Pero de allí no se sigue que Hume esté dispuesto a sacrificar el principio de la libertad por el de la autoridad. Más bien, plantea un equilibrio entre ambos principios: "En todos los gobiernos, hay una perpetua lucha intestina, abierta y secreta, entre la autoridad y la libertad, y ninguna de las dos puede jamás prevalecer absolutamente en la contienda." (Hume, 1992: 40) Ciertamente, cuando se vive en sociedad debe sacrificarse una parte de la libertad personal; pero la autoridad no puede convertirse en absoluta e incontrolable.

Pero entonces ¿cuál es el origen del gobierno? En el libro III del Tratado sobre el entendimiento Humano dedica un apartado (parte 2 sección VII) a este tema. Allí dice que los hombres son movidos en gran medida por el interés y que no extienden su mirada más allá de su persona y del círculo más cercano. Aun así, para mantenerse en sociedad, necesitan respetar algún criterio de justicia. Eso "les evita caer en esa condición miserable y salvaje que es representada comúnmente como estado de naturaleza." (Hume, 2013: 350). El interés propio sigue siendo el mismo. No obstante, ese mismo interés mueve al hombre a preferir vivir en sociedad.

Surge el cuestionamiento, cómo es posible que dentro de la propia sociedad broten desórdenes, existan pasiones y se recurra a la violencia. Hume responde que los hombres son guiados por la imaginación; son atraídos por la representación de un objeto más que por su valor real. Aquello que al individuo le impresiona de manera más vivaz y fuerte prevalece ordinariamente sobre lo que queda en la penumbra: "Todo lo que nos sea cercano en espacio y tiempo incide sobre nosotros con una idea vivaz, ocasiona el efecto correspondiente sobre la voluntad y las pasiones, operando por lo común con mayor intensidad que cualquier otro objeto más distante y oscuro." (Hume, 2013: 351) Nos inclinamos a lo que es más cercano que a lo que es lejano. Nos dejamos llevar más por la apariencia que por la realidad.

Por eso, aun no queriendo, lo hombres actúan en contra de su propio interés. En apariencia "las consecuencias de cada transgresión de la equidad parecen ser muy remotas e incapaces de contrarrestar cualquier ventaja inmediata que podamos obtener de esa violación." (Hume, 2013: 351). Si ese criterio proliferara, las relaciones en sociedad se harían muy peligrosas e inseguras. Los actos de injusticia serían alentados por la falta de sanciones; el transgresor sería imitado con más frecuencia en vista de que nadie lo castiga.

Hume advierte que "los hombres son naturalmente incapaces de preferir lo remoto a lo contiguo." (Hume, 2013: 252) Si no hubiese remedio el caos sería irremediable. La solución que cura la flaqueza y obliga a observar las leyes y la equidad es la institución de la autoridad:

Estas son las personas a quienes llamamos magistrados civiles, reyes, ministros, gobernantes y legisladores, que, siendo personas sin intereses específicos en relación con la mayor parte del Estado, tampoco están interesadas-o este interés es mínimo- en cometer acto alguno de injusticia y que, al estar satisfechas de su condición presente y de su puesto en la sociedad, tendrán un interés inmediato en el continuo cumplimiento de la justicia, tan necesario para el mantenimiento de la sociedad. Este es, pues, el origen del gobierno civil y de la sociedad. (Hume, 2013: 352) 
Los hombres no van a abandonar la mezquindad de preferir lo inmediato por lo remoto. Así están hechos y así continuarán siendo. Ellos no pueden cambiar su naturaleza, pero sí pueden cambiar su situación. (Hume, 2013: 352).

Este autor escocés señala que la ejecución de la justicia es la principal ventaja del gobierno, pero no la única: "Las mismas personas ejecutoras de las leyes de justicia decidirán también todas las controversias en torno a esas leyes, y como son imparciales para con la mayor parte de la sociedad, decidirán de un modo más equitativo de lo que cada uno haría en su propio caso." (Hume, 2013: 353) Por medio de la ejecución y la decisión, los hombres se ven asegurados contra la debilidad consistente en que cada cual busca su propio beneficio; bajo el amparo de los gobernantes los individuos comienzan a gozar de las ventajas de vivir en sociedad.

Y aquí Hume se mueve más allá de la clásica postura liberal según la cual el Estado sólo debe proteger a los individuos. Señala que el Estado tiene la misión de encaminar a los hombres hacia un "fin común": "Pero el gobierno lleva más lejos su influencia benéfica y, no contento con proteger a los hombres mediante las convenciones que ellos mismos han establecido para su mutuo interés, les obliga a menudo a establecer tales convenciones, y les fuerza a buscar su propio beneficio, por medio de la coincidencia en algún propósito o fin común." (Hume, 2013: 353) Es verdad que no hay cosa más funesta que el preferir lo presente a lo distante haciéndonos desear los objetos en virtud de su apariencia en lugar de su valor intrínseco. Y los hombres, por comodidad prefieren descargar en otros las obligaciones que les atañen con la comunidad.

La sociedad política remedia ambos inconvenientes. Los magistrados hallan un interés inmediato en el interés de cualquier parte considerable de sus súbditos. No necesitan consultar sino consigo mismos para formarse un plan que promueva ese interés. Y como el fallo de cualquier miembro en la ejecución está conectado, aunque no inmediatamente, con un fallo en el conjunto, los gobernantes evitan tal cosa, dado que ellos no tienen interés particular alguno, ni inmediato ni remoto. De este modo, se construyen puentes, se abren puertos, se levantan construcciones, se hacen canales, se equipan flotas y se instruye a los ejércitos en todos los países, gracias al cuidado del gobierno, que, aun compuesto de hombres sujetos a todas las flaquezas humanas, en virtud de una de las más finas y sutiles invenciones imaginables se convierte en un cuerpo complejo que en alguna medida se halla libre de todas esas flaquezas. (Hume, 2013: 353)

Estamos ante una argumentación en favor del gobierno como cuerpo político necesario para que los hombres puedan vivir en paz. Ese cuerpo de funcionarios mira al interés general y no al interés particular. Así se posibilita la vida en sociedad bajo el amparo de la justicia; se hace factible que haya una perspectiva que se eleva por encima de lo inmediato y gracias a la cual se garantiza el orden entre las personas con vistas al progreso. Así, los hombres son encaminados hacia ese fin común.

Abundando en su argumentación, este pensador escocés indica que en toda sociedad hay "tres leyes naturales": la estabilidad en la posesión, la transmisión de esa posesión por consentimiento y el cumplimiento de las promesas. Estas leyes son tan importantes que el gobierno se establece, precisamente, para aplicarlas. (González, 2008: 161-196) 
Con todo y lo dicho en contra del contrato y de las promesas encontramos que Hume dice, textualmente, que la fuente primera de la obligación política es una promesa de obediencia a la autoridad:

Una vez que los hombres han advertido lo necesario que resulta el gobierno para mantener la paz y hacer cumplir la justicia, es natural que deseen agruparse, escoger magistrados, determinar su poder y prometerse obediencia. Como se supone que una promesa es un vínculo o factor de seguridad ya en uso, acompañado por una obligación moral, deberá tenerse por la sanción originaria de la función de gobierno, y fuente de la obligación primera de obediencia. (Hume, 2013: 355)

Esta fórmula, sin duda, recuerda el procedimiento contractual. De hecho, Hume destaca que así se conduce uno de los partidos ingleses. Aunque no lo dice con todas sus letras, se refiere al partido Whig que apoyó las tesis de Locke. Y a quien parece citar Hume en el siguiente pasaje:

Todos los hombres han nacido libres e iguales. Sólo por consentimiento pueden establecerse el gobierno y la superioridad. Al instaurarse la función de gobierno, el consentimiento de los hombres impone a éstos una nueva obligación, desconocida por las leyes de naturaleza. Por tanto, los hombres están obligados a obedecer a sus magistrados únicamente porque así lo prometieron, y si no hubieran dado expresa y tácitamente su palabra de mantener obediencia, nunca se habría convertido tal cosa en parte integrante de su deber moral. (Hume, 2013: 355)

No obstante, se apresura a decir que esta conclusión como clave de explicación de todos los gobiernos en todas las épocas sería errónea. Respecto a la teoría de la obediencia en Hume, Geoffrey Marshall observa que el escocés se consideró un hombre "por encima de los partidos." Sin embargo, Hume fue un conservador. Sólo en casos excepcionales y verdaderamente extremos, este pensador utilitarista, acepta la teoría de la resistencia. (Marshall, 1954: 247-248).

El razonamiento de Hume va en el siguiente sentido: aunque el deber de obediencia esté, al principio, implicado en la obligación de las promesas y ese deber sea mantenido durante algún tiempo, la obligación echa raíces a lo largo del tiempo, se vuelve una costumbre: "engendrando una nueva y original obligación y autoridad, con independencia de todo contrato." (Hume, 2013: 355) Se deduce que en su pensamiento la costumbre, no el contrato, es el fundamento del poder político.

De allí que critique a aquellos filósofos que derivan la obediencia a la autoridad de una promesa:

Pero como nosotros nos hemos desengañado ya de este particular y hemos encontrado que tanto la justicia natural como la civil tienen su origen en las convenciones humanas, nos damos cuenta enseguida de lo infructuoso que resulta intentar reducir la una a la otra y buscar en las leyes naturales un fundamento de nuestros deberes políticos más poderosos que el interés y las convenciones humanas, ya que esas mismas leyes están edificadas exactamente sobre la misma base. (Hume, 2013: 356) 
La ley del deber que para los iusnaturalistas es el sustento del acuerdo político, en Hume deja de ser punto de sustentación del Estado; tal soporte se encuentra ahora en el interés, las necesidades y la historia.

La cuestión es que el gobierno, siendo una cosa tan seria, no se puede dejar al capricho y volatilidad de las promesas expresadas en un contrato: "Aun cuando no existieran en el mundo las promesas, el gobierno seguiría siendo algo necesario en toda sociedad numerosa y civilizada." (Hume, 2013: 358)

Y remarca, sería contrario al interés público que se dejase de obedecer a la autoridad establecida por la razón que fuese. En el binomio autoridad-libertad se inclina por preservar el orden. Sólo da cabida a la rebelión cuando hay una clara y evidente afectación del principio de libertad. La cuestión es preservar el orden para que las libertades individuales puedan convivir en armonía. Hace patente la necesidad de que los intereses inmediatos de los individuos no vayan en detrimento del interés de la sociedad.

La adhesión al utilitarismo por parte de Hume es clara: "La distinción entre el bien y el mal morales está basada en el placer o el dolor resultante de la contemplación de un sentimiento o de un carácter. Y como ese placer o dolor no puede serle desapercibido a la persona que lo siente, se sigue que hay exactamente tanta virtud o vicio en un carácter como cada uno coloca en él, siendo imposible equivocarse en este punto." (Hume, 2013: 358) Refrenda la distinción entre el bien y el mal dependiendo del grado de placer o dolor que proporciona una acción, y rechaza que las bases de la asociación política se encuentren en una promesa externada por los individuos a la autoridad pública: la obligación de obedecer a la autoridad civil "no surge de una promesa, pues nadie a quien no se le haya extraviado el juicio por adherirse demasiado estrictamente a un sistema de filosofía ha soñado jamás con atribuir la obediencia civil a ese origen. Ni los magistrados ni los súbditos se hacen esa idea de nuestros deberes civiles." (Hume, 2013: 358) E inmediatamente, sobre el mismo asunto, escribe: "Vemos que los magistrados están tan lejos de derivar su autoridad, y la obligación de obediencia por parte de los súbditos, de la base de una promesa o contrato original, que ocultan en lo posible a su pueblo, y especialmente al vulgo, que su derecho se derive de tal origen." (Hume, 2013: 359) Conviene resaltar aquí, por lo que más adelante diremos, que Hume se refiere, precisamente, al "origen" del Estado en polémica con los contractualistas.

¿Pero entonces - pregunta Hume - un gobierno no tendrá autoridad sobrelas personas si ellas no han dado su consentimiento? En realidad ese requisito del consentimiento como base del gobierno es una cosa que sólo han pensado los contractualistas. Eso de rebelarse contra la autoridad porque no hay algún registro del contrato social es, simplemente, un dislate. Para él, el honor y la obediencia civil son el fundamento de las instituciones públicas.

Hume recurre a otro argumento contra el contractualismo, la lógica jurídica: los contrayentes de un contrato se obligan de manera mutua. Pero, si alguna de las partes no cumple con lo pactado, el acuerdo se rompe: "al ser condicional, deja de ser vinculante, cuando la otra parte contratante no cumple con su compromiso." (Hume, 2013: 360) El problema es que el Estado no puede depender del capricho de las personas; cualquier porción de agitadores podría hacer caer al poder público convenciendo a los ciudadanos 
de que retiren su consentimiento. A su parecer, allí está el punto débil del argumento contractualista: depender para estos menesteres tan delicados de la voluntad de las personas es riesgoso. Como dice John Rawls al estudiar a Hume:

En consecuencia, la conclusión de Hume es que como doctrina filosófica, el contrato social no sólo es inverosímil y contradictorio para el sentido común en cuanto va en contra de cualquier tipo de cuestiones que el pueblo realmente cree, y se mueve en oposición a la opinión general, como él argumenta en las partes iniciales del Ensayo, sino que, además, es superficial en cuanto fracasa al tratar de arrojar luz sobre lo que realmente es el ámbito de la obligación política, vale decir, las necesidades generales y los intereses de la sociedad. (Rawls, 2007: 170)

Hume llama a la conformación del vínculo político, "principio natural" ante todo porque está basada en el interés inmediato del sujeto; o sea, preservar su persona y sus bienes. En rigor, hay que asegurar la estabilidad social frente a la eventualidad.

Poco más adelante, Rawls toca la crítica que Hume hace de las tesis de Locke al decir que van en contra de la práctica general y de la opinión común. Y agrega:

¿Cómo tendríamos que tomar la crítica que Hume endereza a Locke? Su crítica es robusta y convincente, o por lo menos altamente plausible bajo muchos supuestos, pero débil en otros. Pienso que debería ser señalado que el ensayo de Hume (y el posterior ensayo de Bentham, aunque este último autor dice esencialmente lo mismo que Hume) fue históricamente muy influyente en minar la perspectiva del contrato social. Ya no hubo, por lo menos en Inglaterra, sucesores de doctrina como la enarbolada por Locke. Con esta evidencia podemos decir que el ensayo de Hume fue históricamente muy efectivo. (Rawls, 2007: 170)

Sin duda, el utilitarismo, junto con el historicismo de Hegel y Marx fueron las doctrinas que echaron abajo la larga hegemonía ejercida por el iusnaturalismo durante, como hemos dicho, los siglos XVII y XVIII.

No obstante, en el mundo de las ideas, hay un constante nacer y renacer de corrientes. Y fue, precisamente, John Rawls quien ayudó a la recuperación del contractualismo con base, precisamente, en una robusta y convincente crítica al utilitarismo (1971: 22-40)

\section{Conclusiones}

La solución de los problemas individuales, de acuerdo con Hume, se encuentra en la institución de una autoridad que mire al interés común. Los funcionarios, de acuerdo con su planteamiento, tendrán el encargo de velar por la paz y la concordia. Pero cabe la pregunta ¿qué sucedería si esos funcionarios caen en la tentación de ver por sus intereses particulares y abandonan el interés común? En sus escritos no hay traza de algún mecanismo preventivo o punitivo que salvaguarde a la sociedad de ese peligro. La corrupción de los gobernantes es un hecho histórico que ha dado lugar, precisamente, a la distinción entre formas malas y formas buenas de gobierno. 
Ciertamente, Hume habla de la tiranía y el despotismo. En la eventualidad de que surjan esos regímenes, como hemos visto, admite el derecho de resistencia. Pero no se ocupa de algunas medidas precautorias para evitar su aparición cosa que sorprende en vista de que estamos frente a uno de los grandes pensadores de la filosofía política.

Acaso, la explicación se encuentre en que tuvo más cuidado en atender la polémica en contra de los pensadores contractualistas y encontrar la forma de cimentar una teoría alternativa, precisamente, al contrato social. Al respecto, en sus escritos se encuentran tres tipos de argumentaciones contra la doctrina rival: histórica, filosófica y de sentido común (social).

1. Histórica: el contractualismo es una creencia que no encuentra corroboración empírica. Recurre en repetidas ocasiones a la historia para mostrar que un hecho así no tiene algún sustento.

2. Filosófica: La crítica de Hume a la teoría del contrato social desde la óptica utilitarista se centra en sustituir el deber por el interés. Dice que los individuos son llevados a procurar el interés particular, inmediato y visible; no son capaces de apreciar el interés lejano y borroso. Pero, para solucionar las diferencias, tienen que recurrir a la justicia, de otra manera los hombres perecerían.

3. De sentido común (social): También echa mano de la opinión de la gente de a pie, a la cual si se le preguntara si dio su consentimiento a la autoridad constituida dirá que no. El hábito de obedecer es una cosa tan arraigada en las personas que no tiene sentido recurrir a una tema tan sofisticado y extraño como lo es un supuesto acuerdo entre los gobernantes y los gobernados.

En nuestra opinión, ante una concepción tan bien planteada como la de Hume, debemos recurrir a la distinción hecha por Norberto Bobbio en el sentido de que una cosa es el origen del poder político y otra cosa distinta es su fundamentación (Bobbio y Bovero, 1985). Con base en esta distinción, podemos advertir que, de suyo, el origen del Estado ciertamente es histórico; pero en cuanto a su fundamentación encontramos que, a lo largo de la historia, se registran ciertas creencias que han sido tomadas como válidas para establecer la legitimidad de la autoridad política. Entre esas creencias encontramos, por ejemplo, el origen divino de los reyes que durante siglos fue asumido como un principio de validez de la autoridad política. Tal principio no necesitó comprobación histórica alguna para ser tomado como verdadero.

Ciertamente, en grupos humanos poco desarrollados como los indios americanos (citados por Hume) quienes ostentaban la fuerza eran quienes mandaban. Pero, como dice Gaetano Mosca:

Ocurre, inexorablemente, o al menos ha ocurrido hasta ahora en todas las sociedades algo numerosas y recién llegadas a cierto grado de cultura, que la clase política no justifica exclusivamente su poder con sólo poseerlo de hecho, sino que procura darle una base moral y hasta legal, haciéndolo surgir como consecuencia necesaria de doctrinas y creencias generalmente reconocidas y aceptadas en la sociedad regida por esa clase política. (Mosca, 1992: 131) 
El trabajo de los iusnaturalistas se sitúa en el terreno de la fundamentación racional del poder político, no en el campo de la explicación histórica del origen del Estado. Ninguno de ellos cayó en la ingenuidad que les achaca Hume de recurrir al contrato social como mecanismo de interpretación empírica.

$\mathrm{Si}$, en todo caso, queremos hablar de alguna utilidad histórica de las doctrinas contractualistas, esa utilidad tiene que ser ubicada en la polémica contra, precisamente, las doctrinas que sostuvieron el origen divino de los reyes. Los filósofos del derecho natural abanderaron la idea, a contrapelo de las posiciones teológicas, que no era la voluntad de Dios, sino la voluntad de los hombres el sostén del poder político y que, en consecuencia, los individuos tenían ciertos derechos que reclamar frente al Estado. Es más, el Estado se constituía para beneficio de las personas. Los contractualistas hablaron de las personas como seres con una igual dignidad y libertad frente a la estratificación social propia de la época medieval. Como una hipótesis racional que debía tener consecuencias prácticas. En tal virtud el contractualismo representó una verdadera y propia revolución copernicana: la fuente de legitimidad del poder política ya no fluiría de arriba hacia abajo, sino al revés, de abajo hacia arriba. La modernidad política tiene entre sus grandes logros, justamente, el haber invertido completamente la fuente de legitimidad del poder político respecto del mundo medieval.

De hecho, la Constitución de los Estados Unidos (1787) se basa en los postulados iusnaturalistas, lo mismo que la Declaración de los Derechos del Hombre y del Ciudadano de la Revolución francesa (1789) así como las subsecuentes constituciones de las antiguas colonias españolas.

Hume criticó a los contractualistas por no haber cimentado sobre bases empíricas sus planteamientos. Jamás entendió que el pacto, tal como lo idearon los iusnaturalistas, no es un evento empírico sino un postulado normativo que, en cuanto tal, vale independientemente de la experiencia. (Bobbio, 1969: 215) Y aunque el contrato no tiene una base de demostración como hecho histórico, sí tuvo consecuencias prácticas. Así lo entendió Sir Ernest Barker quien en los primeros renglones de la "Introducción" al libro Social Contract (Locke, Hume, Rousseau) escribe:

Incluso si jamás hubo un contrato, los hombres en realidad se comportan "como si" hubiese habido tal cosa; y comportándose y actuando en términos del cuasi-contrato - o lo que los juristas llaman 'el contrato implícito en la ley' una idea que acaso pueda ser ampliada para cubrir el caso del 'contrato implícito en el gobierno'-ellos proceden en términos de este cuasi-contrato que sirve bien para alcanzar propósitos admirables. Quizá la teoría del Contrato Social pueda ser mecánica, jurista y a prio$r i$, pero, con todo y eso, fue una manera de expresar dos ideas o valores fundamentales a los que la mente humana siempre se aferra, esto es, el valor de la libertad, o la idea de que la voluntad, no la fuerza, es la base del gobierno, y el valor de la justicia, o la idea de que el derecho, no el poder, es la base de toda sociedad política y de todo sistema de orden político. (Baker, 1960: VII-VIII)

¿Pero si no es el contrato, entonces, cuál es el fundamento del poder según Hume? Como hemos visto a lo largo de este análisis, la respuesta no es sencilla: a veces dice que los hombres se reunieron para concertar un acuerdo. (Y allí se le vuelve a meter 
el expediente contractual). Pero luego da un paso atrás y dice que es el interés, las necesidades y la costumbre.

Como Hume no logra salir del marco empírico y tiene que moverse en el plano histórico entonces explica que los intereses individuales chocan y, en consecuencia, las personas se ven forzadas a nombrar magistrados que vean más allá de lo inmediato para procurar el interés común.

En su razonamiento se percibe, pues, una tensión entre la descalificación del contractualismo y un razonamiento basado en el choque de intereses individuales que exigen, a querer o no, un acuerdo entre tendencias discordantes.

La supuesta demolición por parte de Hume de la doctrina contractualista que tanto presumió Bentham, a nuestra manera de ver, no es tal; quedó mal cimentada. Tanto así que, a final de cuentas, el propio Hume tuvo que resignarse a recurrir a ella como clave de explicación de los fundamentos del Estado aunque no fuese de manera teórica, sino de manera empírica.

\section{Bibliografía}

Aristóteles (1988): Política, Madrid, Gredos

Baker, Sir E. (1960): “Introduction”, Social Contract (Locke, Hume, Rousseau), Oxford, Oxford University Press.

Bentham, J. (1948): The Principles of Morals and Legislation, New York, Hafner Press.

Bentham, J. (2010): Un fragmento sobre el gobierno, Madrid, Tecnos.

Bobbio J. (1969): Diritto e stato nel pensiero di Emanuele Kant, Torino, Giappichelli

Bobbio, N. (1973): Società e Stato da Hobbes a Marx, Torino, Università degli Studi di Torino

Bobbio, N. (1979): "Thomas Hobbes", en AA.VV, Storia delle idee politiche, economiche e sociali (volumen III), a cargo de Luigi Firpo, Torino, Utet.

Bobbio N. y M. Bovero (1979): Bobbio, N., "Il modelo giusnaturalistico", Società e Stato nella Filosofia Politica Moderna, Milano, Il Saggiatore.

Bobbio, N. y M. Bovero (1985): Origen y Fundamentos del Poder Político, México, Grijalbo.

Brownsey, P. F. (1978): "Hume and the Social Contract", Philosophical Quarterly, 28 (111). Disponible en:

http://pq.oxfordjournals.org/

Fernández Santillán, J. (1988): Hobbes y Rousseau (Presentación de Norberto Bobbio), México, Fondo de Cultura Económica.

Fernández Santillán, J. (1996): Locke y Kant (Presentación de Michelangelo Bovero), México, Fondo de Cultura Económica.

Fernández Santillán, J. (2011a): Norberto Bobbio: el filósofo y la política (Antología), México, Fondo de Cultura Económica.

Fernández Santillán, j. (2011b): "Bobbio nel mondo iberoamericano", en Bovero, M. (ed.), El Futuro di Norberto Bobbio, Roma-Bari, Laterza.

González, A.M. (2008): "Naturaleza y función del gobierno en Hume", Revista de filosofia, 33 (1), 2008. 
Hobbes, Th. (1971): "Elementotum Philosophiae sectio tertia De Cive", Opere Politiche, (Firpo, L., ed.) Torino, Utet.

Hobbes, Th. (1982): Leviathan, New York, Penguin Books.

Hume, D. (1986): Enquiry concerning the principles of moral, Oxford, Clarendon Press.

Hume, D. (1992): Essays, Moral, Political and Literature, Indianapolis, Liberty Fund.

Hume, D. (2013): A Treatise of Humane Nature, San Bernardino, California, Kindle Edition.

Locke, J. (1980): Two Treatises of Government, Cambridge, Cambridge University Press.

Marshall, G. (1954): "David Hume and the Political Scepticism", Philosophical Quarterly, (4). Disponible en: http://pq.oxfordjournals.org

Mosca, G. (1992): La clase política, México, Fondo de Cultura Económica.

Rawls, J. (1971): A Theory of Justice, Cambridge, Massachusetts, The Belknap Press of Harvard University Press.

Rawls, J. (2007): Lectures on the History of Political Philosophy, Cambridge, Massachusetts, The Belknap Press of Harvard University Press.

Rousseau, J.J. (1964a): "Sur L'Origine et les Fondemens de L'Inegalité parmi les Hommes", Oeuvres complètes, III, Paris, Gallimard, Bibliothèque de la Pléiade.

Rousseau, J.J. (1964b): "Du Contrat Social”, Oeuvres complètes, III, Paris, Gallimard, Bibliothèque de la Pléiade.

Rousseau, J.J. (1969): "Émile", Oeuvres complétes, IV, Paris, Gallimard, Bibliothèque de la Pléiade.

Tarantino, G. (1905): Saggio sulle idee morali e politiche di Tomasso Hobbes, Napoli, Francesco Giannini \& Figli.

Weber, M. (1969): "La política como vocación", El político y el cientifico, Madrid, Alianza Editorial. 